\title{
When good is good: A virtuous circle of self- efficacy and flow at work among teachers
}

\author{
Alma Rodríguez-SáncheZ ${ }^{1}$, Marisa Salanova ${ }^{1}$, Eva Cifre $^{1}$ AND \\ WILMAR B. SCHAUFELI ${ }^{2}$ \\ ${ }^{1}$ Universitat Jaume I, Spain; ${ }^{2}$ Utrecht University, The Netherlands
}

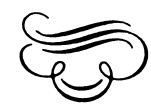

Resumen

The objective of this study was to extend the channel model of flow (Csikszentmihalyi, 1975, 1990) by including self-efficacy as predictor of the challenges-skills combination, and of the flow experience itself, based on the predictions of social cognitive theory (Bandura, 1997, 2001). We conducted a two-wave longitudinal study among 258 secondary school teachers. Results, first, showed that the channel model of flow, including self-efficacy as antecedent of flow, fitted better the data. Secondly, it was observed that the more self-efficacy the more flow frequency and higher levels of challenge and skills which, in turn, predicted flow over time. Moreover, the influence of self-efficacy on flow over time was mediated by subjects' perception of the challenges and skills combination. Finally, we discuss the theoretical and practical implications of integrating flow theory into the social cognitive theory.

Keywords: Challenge, flow experience, positive psychology, self-efficacy, skills.

\section{Cuando lo bueno es bueno: el círculo virtuoso de autoeficacia y flow entre profesores}

\begin{abstract}
El objetivo del presente trabajo es extender el modelo de canal de la experiencia de fluir (flow) (Csikszentmihalyi, 1975, 1990) basándonos en la teoría social cognitiva (Bandura, 1997, 2001) e incluyendo la autoeficacia como predictor de la combinación reto y habilidades, y de la experiencia de fluir (flow). Para ello se llevó a cabo un estudio longitudinal con dos tiempos en una muestra de 258 profesores de educación secundaria. Los resultados mostraron que el modelo que extiende el modelo de canal de la experiencia de fluir (flow), incluyendo la autoeficacia como antecedente del fluir (flow), se ajusta mejor a los datos. Además, se observó que a más autoeficacia más frecuencia de fluir (flow) y mayores niveles de reto y habilidades, que a su vez predecían fluir (flow) en el tiempo. Así, la influencia en el tiempo de las creencias de eficacia en el fluir (flow) estaba mediada por la percepción de la combinación de reto y habilidades. Finalmente se discuten implicaciones teóricas y prácticas de la integración de la teoría de la experiencia de fluir (flow) en la teoría social cognitiva.

Palabras clave: Reto, experiencia de flow, psicología positiva, autoeficacia, habilidades.
\end{abstract}

\footnotetext{
Acknowledgements: This study was supported by a grant from the Spanish Ministry of Work and Social Affairs (\#411/UJI/SALUD), Spanish Ministry of Science and Innovation (\#PSI2008-01376/PSIC), and Universitat Jaume I \& Bancaixa (\#P11B2008-06).

Correspondencia con los autores: Alma M. Rodríguez-Sánchez, PhD. Department of Social Psychology. Universitat Jaume I. Av. Sos Baynat, s/n. E-12071. Castellón, Spain. Telephone: + 34964729569 ; Fax: + 34964729262 . E-mail: Alma.Rodriguez@psi.uji.es

Original recibido: 30/11/2010. Aceptado: 07/01/2011
} 
Since the beginning of this century, increased attention has been paid to what has been coined Positive Psychology: the scientific study of human strength and optimal functioning (Seligman \& Csikszentmihalyi, 2000). This approach is considered to supplement the traditional focus of psychology on disease, damage, disorder, and disability. Therefore, those organisations interested in improving the quality of their employee's working life have to optimise positive psychosocial emotions and experiences. Concepts such as job satisfaction, work engagement and flow at work are increasingly relevant to generate healthy jobs, employees, and organisations (Bryce \& Haworth, 2002; Nelson \& Simmons, 2002). In the current study, we focus on the factors that may promote individual flow experiences expanding the channel model of flow Csikszentmihalyi $(1975,1990,1997)$ by including self-efficacy as antecedent.

\section{WHAT IS FLOW? OPERATIONALISATION OF OPTIMAL EXPERIENCES AT WORK}

The optimal experience of flow is complex and difficult to measure because of its ephemeral and temporary nature. In fact, the literature offers a number of flow definitions; but the most prominent conceptualization used is the one that defines Flow experience as an optimal and momentary experience in connection with a specific activity where the person is totally focused and absorpted in the activity at hand and experience enjoyment while performing it (Chen, 2006; Csikszentmihalyi, 1990; Ghani \& Deshpande, 1994). Although operationalisation of flow is still a topic of discussion, we critically examined previous literature to shed some light on it. This examination revealed that recent research agrees with the cognitive, motivational and emotional components of optimal experience (for example, Bassi, Steca, Delle Fave, \& Caprara, 2007; Delle Fave \& Massimini, 2004).

Despite the fact that the first studies on flow were carried out mainly in creative and sports settings, researchers formed a picture of the general characteristics of optimal experience, and found that the flow experienced while undertaking entertainment and work activities was quite similar (Nakamura \& Csikszentmihalyi, 2002). For instance Bakker (2005), and Salanova, Bakker and Llorens (2006), developed the flow concept during work activities and defined it as an optimal experience at work that is characterised by work enjoyment (i.e., the emotional component), absorption (i.e., the cognitive component) and intrinsic interest (i.e., the motivational component).

However, a recent study which compared two competitive models of flow with three (i.e., enjoyment, absorption and intrinsic interest) - and two- (i.e., enjoyment and absorption) factor models, and showed a better fit of the last one, pointing out that intrinsic interest (i.e., the motivational component) was not part of the flow experience itself (Rodríguez-Sánchez, Cifre, Salanova, \& Åborg, 2008).

To sum up, focusing on the work domain, absorption refers to a state of total concentration whereby employees are totally immersed in their work. In this situation, time flies and they forget everything else around them (cf. Csikszentmihalyi, 1990), and people enjoy doing the activity at hand (Ghani \& Deshpande, 1994). This involvement at the activity is so deep that nothing else seems to matter at the time and seems to be the central aspect of the flow experience (Csikszentmihalyi, Rathunde, \& Whalen, 1993). Once defined flow experience, the next issue is to investigate which are the conditions required to experience flow at work.

\section{THE CHANNEL MODEL OF FLOW}

The first studies on flow by Csikszentmihalyi (1975) considered flow as the situation where activity challenges are matched with person's skills. Csikszentmihalyi formed a model based on this challenge-skill ratio which was coined "channel model of flow". In subsequent studies, this channel model of flow has been tested and Csikszentmihalyi 
and Csikszentmihalyi (1988) pointed out that to experience flow, challenges and skills must not only be in balance, but must also exceed levels in such a way that one must increase the complexity of the activity by developing new skills and taking on new challenges. Then when both challenges and skills are high, the flow experience is likely to arise (Csikszentmihalyi \& LeFevre, 1989; Delle Fave \& Bassi, 2000).

It is important to bear in mind that the combination of perceived challenges and skills seem to be antecedents and prerequisites of the flow experience (Nakamura \& Csikszentmihalyi, 2002), and that although they are necessary, they are not the only existing prerequisites of the flow experience. For instance, situational conditions (i.e., clear goals and immediate feedback), and also personal conditions (i.e., skills/abilities, and efficacy beliefs) are important antecedents that can enhance flow (Bassi et al., 2007; Salanova et al., 2006; Sawyer, 2003; Shin, 2006).

In the present study we will only focus on a specific personal condition (self-efficacy) due to the limited studies existing about it regarding flow.

\section{EFFICACY BELIEFS AND FLOW}

According to the social cognitive theory (SCT) (Bandura, 1997, 2001), self-efficacy is defined as: “...beliefs in one's capabilities to organise and execute the courses of action required to produce given attainments" (Bandura, 1997, p. 3). Beliefs about one's own efficacy contribute to motivation by influencing: (a) the challenges people pursue, (b) the effort they expend, (c) their perseverance in the face of difficulties and (d) how people feel while doing the activity. Whatever the other factors which serve as guides and motivators, they are rooted in the core belief that one has the power to produce desired effects by one's actions; otherwise, one has little incentive to act or to persevere in the face of difficulties. Hence, self-efficacy could influence the way that people perceive challenges according to their skills and, in turn, could lead people to experience the psychological state of flow. Therefore, self-efficacy may be considered an antecedent of flow experience.

Moreover, one of the sources of efficacy beliefs is positive psychological states; for instance, when people feel happy doing a task, it positively influences their efficacy beliefs, but when they feel anxious, this influence is negative. This influence is reciprocal because efficacy beliefs also make people feel better. For example, high levels of efficacy beliefs have a positive impact on employee well-being, such as job satisfaction (Grau, Salanova, \& Peiró, 2001), job engagement (Llorens, Schaufeli, Bakker, \& Salanova, 2004; Salanova, Llorens, Cifre, Martínez, \& Schaufeli, 2003; Salanova, Llorens, \& Schaufeli, 2011; Salanova, Schaufeli, Xanthopoulou, \& Bakker, 2009) and also on flow experiences in academic settings (Bassi et al., 2007; Salanova et al., 2006).

However, past research failed to simultaneously test both antecedents of flow experiences, that is, the challenges and skills combination and efficacy beliefs.

\section{THE PRESENT STUDY}

Based on previous research, the aim of the current study is to integrate efficacy beliefs following the social cognitive theory (Bandura, 1997) into channel model of flow (Csikszentmihalyi, 1990, 1997, 2003) to examine a reciprocal structural model of gain cycles and spirals of efficacy beliefs, challenge and skills, and flow experience. Specifically, and based on Bandura's SCT, we test how efficacy beliefs (i.e., self-efficacy) influence flow experiences (i.e., absorption and enjoyment) both directly and indirectly, through their impact on challenge and skills over time. Therefore, we assume that self-efficacy predicts flow experience not only directly, but also indirectly through the challenges and skills combination over time in a kind of virtuous circle. To note that we examine this relationship regarding to the teaching specific domain, then assuming flow experience like a disposition linked to the teaching group of activities (Jackson \& Eklund, 2002). 
More specifically we expect that:

Hypothesis 1: The extended channel model of flow, which includes self-efficacy as a predictor of flow experience, will fit the data better than the original channel model of flow (only the challenges and skills combination).

Hypothesis 2: Self-efficacy and the challenges and skills combination are positively related to flow (at T1 and T2). That is, the more self-efficacy, the higher levels of challenges and skills and the more flow at T1, and the same occurs at T2.

Hypothesis 3: Self-efficacy and flow will both be reciprocally related in a kind of virtuous circle over time. That is, the more self-efficacy at T1, the more flow experiences at $\mathrm{T} 2$, and vice versa.

\section{METHOD}

\section{Sample and Procedure}

The sample at time 1 (T1) comprised 483 teachers (56\% women) from 34 different secondary schools ( $81 \%$ response rate) who filled the self-report questionnaires at the beginning of the academic year. Ages ranged from 23 to 60 years $(M=40.2 ; S D=8$ years and 2 months); $87 \%$ held a master's degree, and, $83 \%$ worked in public schools. Eight months later 258 secondary school teachers (57\% women) from 24 of the originally secondary schools participated in the longitudinal study. Accordingly, 53\% of the teachers who participated at T1 also participated at T2. Ages ranged from 23 to 60 years ( $M=40 ; S D=8$ years and 2 months).

In order to test whether drop-outs differed from the panel group, we compared the T1 background variables of both groups (i.e., age, gender, type of school -private vs. public-, teaching experience and organizational tenure), as well as the main psychosocial variables considered in the study. The results of the Multiple Analyses of Variance showed that there were no significant differences between the groups regarding the background variables $[F(5,418)=1.11, p=.35]$ or the study variables (i.e., self-efficacy, challenges and skills, enjoyment, absorption) $[F(5,461)=1.28, p=$ .27]. Moreover, we also conducted Analyses of Variance to control for background variables (i.e., gender, age, teaching experience and type of school) on T1 and T2 flow variables. Thus, we did not find any significant differences on the study variables ${ }^{1}$.

\section{Measures}

\section{Self-efficacy (SE)}

We measured it by adapting the general self-efficacy scale (10 items; 0 never to 6 always) from Schwarzer (1999) to a more specific measure of teacher's self-efficacy. Namely, we rephrased the general version items to match them to the specific context of teaching. For instance, we changed I can solve most problems if I invest the necessary effort to I can solve most problems in my teaching job if I invest the necessary effort.

\section{Flow experience}

We used two short flow scales to measure Absorption and Enjoyment. We assessed absorption by 6 items from an adapted Spanish version of the Absorption Dimension of the Utrecht Work Engagement Scale (UWES; Schaufeli, Salanova, González-Romá, \& Bakker, 2002), taking into account not a general state at work (engagement) but a specific domain and temporal experience (flow) (see Demerouti, 2006). An example of an item is: When I am working, I forget everything else around me. We assessed enjoyment by 4 items adapted from the enjoyment scale validated by Rodríguez-Sánchez et al. (2008). An example of an item is: I feel happy while I am working. Participants indicated 
the frequency of these experiences of enjoyment and absorption during the preceding week on a 7-point frequency rating scale ranging from 0 (never) to 6 (every day).

\section{Challenge}

We assessed it by 2 self-constructed item measures which referred to the level of challenge and inspiration that work implies for employees. The items were $M y$ job provides me with new challenges and My job is stimulating and inspires me. We measured Skills by 6 items from an adapted Spanish version of the Perceived Competence Scale from the Maslach Burnout Inventory-General Survey (MBI-GS; Salanova, Schaufeli, Llorens, Peiró, \& Grau, 2000; Schaufeli, Leiter, Maslach, \& Jackson, 1996). An example of an item is In my opinion, I am good at my work. Participants indicated the extent to which they agreed with each sentence on a seven-point rating scale $(0=$ never, $6=$ every day $)$ in both scales of challenges and skills.

According to the channel model of flow (Csikszentmihalyi, 1990, 1997), flow is likely to arise when people show high levels of challenges well matched with high levels of skills. Therefore, we used the multiplicative variable Challenges and Skills variable as a way to measure the higher levels of both variables in combination; in other words, measuring the multiplicative factor for challenge and skills we try to find the high levels of both the challenges and skills that would lead to experiencing flow.

\section{Data Analyses}

Firstly, we computed internal consistencies (Cronbach's $\alpha$ ) and descriptive analyses. Secondly, we performed Confirmatory Factorial Analyses (CFA), implemented by the AMOS program (Arbuckle \& Wothke, 1999) to test a measurement model that distinguishes among the constructs of self-efficacy and perceived competence (for measuring levels of skills) (Caprara, Pastorelly, Regalia, Scabini, \& Bandura, 2005). Moreover, although the bi-factorial structure of flow experience (absorption and enjoyment) was tested in previous studies (see Rodríguez-Sánchez et al. 2008); we also tested in this sample the good adjustment of fit of the bi-factorial structure among teachers.

Thirdly, we used Structural Equation Modelling (SEM) methods also by AMOS, to test our two-wave longitudinal hypotheses. We followed these steps: Firstly, the Stability Model (M1) was tested without cross-lagged structural paths, but with temporal stabilities and synchronous correlations. Temporal stabilities were specified as correlations between the corresponding constructs at T1 and T2. M1 estimated the total stability coefficient between $\mathrm{T} 1$ and $\mathrm{T} 2$ without specifying the variance in direct or indirect paths (Pitts, West, \& Tein, 1996). Secondly, the fit of this stability model was compared to the three more complex models: (1) the Causality Model (M2), which is identical to M1 but includes additional cross-lagged structural paths from T1 selfefficacy to T2 challenges X skills and to T2 flow, as well as from T1 challenges X skills to T2 flow; (2) the Reversed Causation Model (M3) which is also identical to M1, but includes additional cross-lagged structural paths from T1 challenges X skills to T2 self-efficacy, as well as from T1 flow to T2 self-efficacy and T2 challenges X skills; (3) the Reciprocal Model (M4), which includes reciprocal relationships among self-efficacy, challenges $\mathrm{X}$ skills and flow and, therefore, includes all the paths of $\mathrm{M} 2$ and $\mathrm{M} 3$.

We tested different fit indices: the $\chi^{2}$ Goodness-of-Fit Statistic, Goodness-of-Fit Index (GFI), Adjusted Goodness-of-Fit Index (AGFI), the Root Mean Square Error of Approximation (RMSEA), the Comparative Fit Index (CFI), the Incremental Fit Index (IFI) and the Tucker-Lewis Index (TLI). Values smaller than .08 for RMSEA indicate an acceptable fit. For the remaining indices, values greater than .90 indicate a good fit (Hoyle, 1995). Finally, we computed the Akaike Information Criterion (AIC; Akaike, 1987) and Expected Cross-Validation Index (ECVI) to compare non nested competing models. The lower the AIC and ECVI indices, the better the fit of the model to the data. 


\section{Revista de Psicología Social, 2011, 26 (3), pp. 427-441}

Finally, a repeated measures by Multiple Analyses of Variance (MANOVA) was conducted to assess if there were significant differences on the intra-subjects dynamic in the variables of the study (self-efficacy, challenges and skills, enjoyment and absorption) over time. Also, different Analyses of Variance (ANOVA) and contrasts intra-subjects were performed in order to know the trends of each variable over time.

\section{RESULTS}

\section{Preliminary analyses}

Following Caprara et al. (2005), Confirmatory Factor Analyses (CFA) were computed to differentiate the constructs of self-efficacy and perceived competence (for measuring levels of skills). Table I presents the results of the CFA tested between selfefficacy and perceived competence. The chi-square $\left(\chi^{2}\right)$ of all the models was statistically significant; the oblique model showed the best fit indices (see AIC; Akaike, 1987) and met the criteria. These results stress that self-efficacy and perceived competence were interrelated but had distinct constructs.

TABLE I

Fit indices of confirmatory factor analyses $(n=258)$

\begin{tabular}{lccccccccc}
\hline Models & $\chi^{2}$ & $d f$ & GFI & AGFI & RMSEA & CFI & IFI & TLI & AIC \\
\hline 1. Unique factor model & 289.45 & 99 & .87 & .82 & .09 & .92 & .92 & .90 & 363.45 \\
2. Orthogonal model & 327.45 & 99 & .86 & .81 & .10 & .90 & .90 & .88 & 401.45 \\
3. Oblique model & 246.14 & 98 & .88 & .84 & .08 & .94 & .94 & .92 & 322.15 \\
\hline
\end{tabular}

Note. $\chi^{2}=$ Chi-square; $\mathrm{df}=$ degrees of freedom; GFI = Goodness-of-Fit Index; AGFI = Adjusted Goodness-of-Fit Index; RMSEA = Root Mean Square Error of Approximation; CFI = Comparative Fit Index; IFI = Incremental Fit Index; TLI = Tucker-Lewis Index; AIC = Akaike Information Criterion.

Regarding the CFA analyses for the bi-factorial structure of flow experience, we also confirmed on this sample the good adjustment of fit of the bi-factorial structure $\left(\chi^{2}=\right.$ $73.88 ; d f=31 ; p=.000 ;$ RMSEA $=.07 ; \mathrm{GFI}=.9 ; \mathrm{AGFI}=.9 ; \mathrm{CFI}=.97 ; \mathrm{IFI}=.97$; $\mathrm{TLI}=.95)$.

\section{Descriptive Analyses}

Table II displays the means, standard deviations, internal consistencies (Cronbach's $\alpha$ ), stabilities and intercorrelations for the scales in the longitudinal study among secondary school teachers. All the a values met the criterion of .70 . To note that due to the challenge scale is made by two items, results represent the inter-correlation between the items that is also significant. As expected, the pattern of correlations showed that all the scales were significantly and positively related, both between variables and between variables over time. The common method variance test for the T1 variables, using Harman's single factor test with the CFA (e.g. Iverson \& Maguire, 2000), reveals that one single factor could not account for the variance in the data [Delta $\chi^{2}(2)=$ $102.45, p<.001]$. Consequently, our dataset apparently presents no problems in terms of common method variance.

\section{The Hypothesised Structural Model}

First of all, the channel model of flow, including the multiplicative challenges and skills combination as a predictor of flow experience, was tested using longitudinal SEM with two waves. As seen from Table III and Figure 1, the Reciprocal Model (M4) data fit was superior to the rest of the models. However, although the fit indices (CFI, IFI, TLI, AIC and ECVI) were acceptable, the RMSEA exceeded the .08 criterion. So even 
Self-efficacy and flow at work / A. Rodríguez-Sánchez et al.
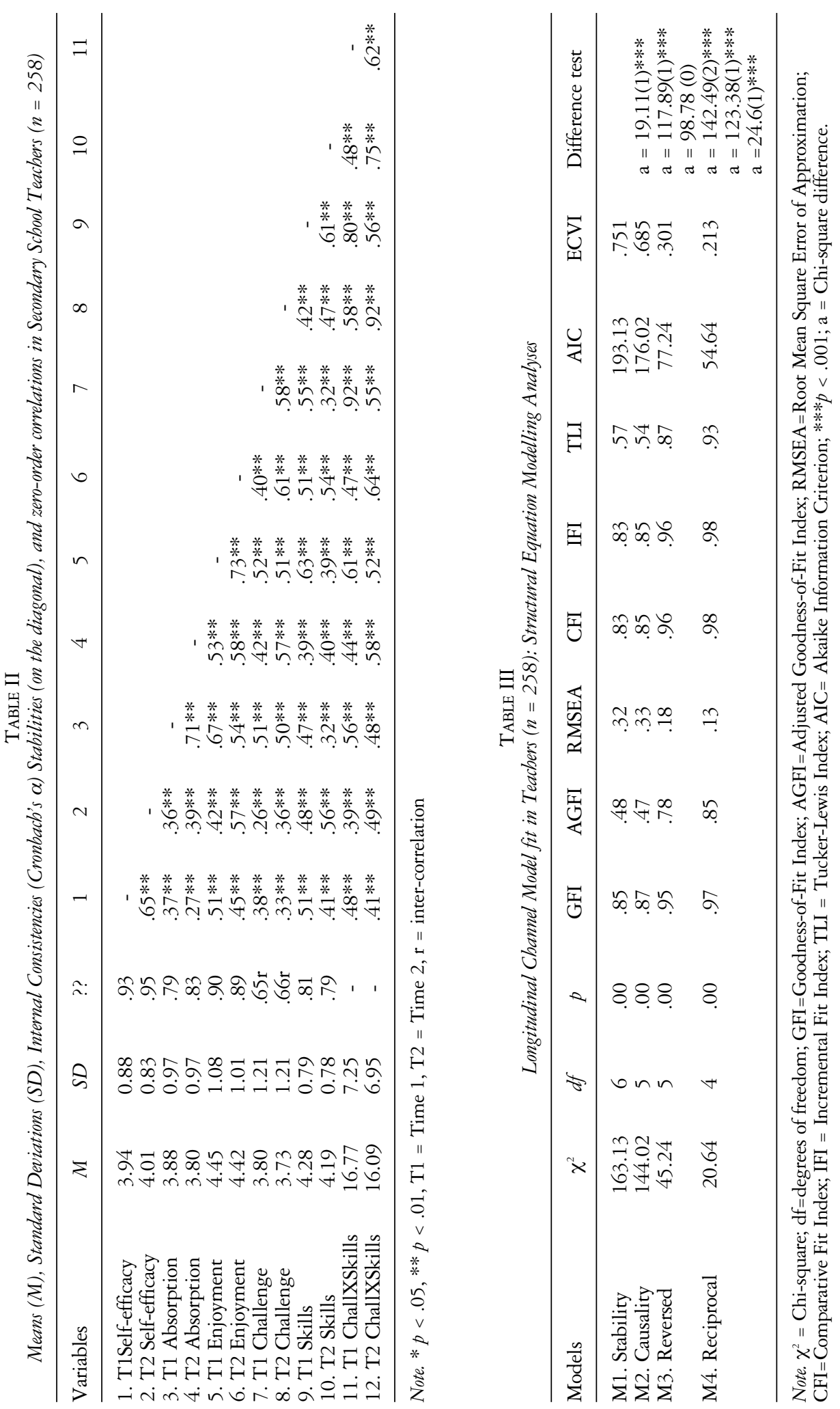


\section{Revista de Psicología Social, 2011, 26 (3), pp. 427-441}

when constraining the model, this channel model of flow presented some deficiencies as values greater than .1 should lead to model rejection (Browne \& Cudeck, 1993).

FIGURE 1

Longitudinal Channel Model including the multiplicative challenges and skills combination as a predictor of flow experience which results from the Structural Equation Modelling Analyses (SEM) in 258 secondary school teachers. Only significant paths are shown in this figure

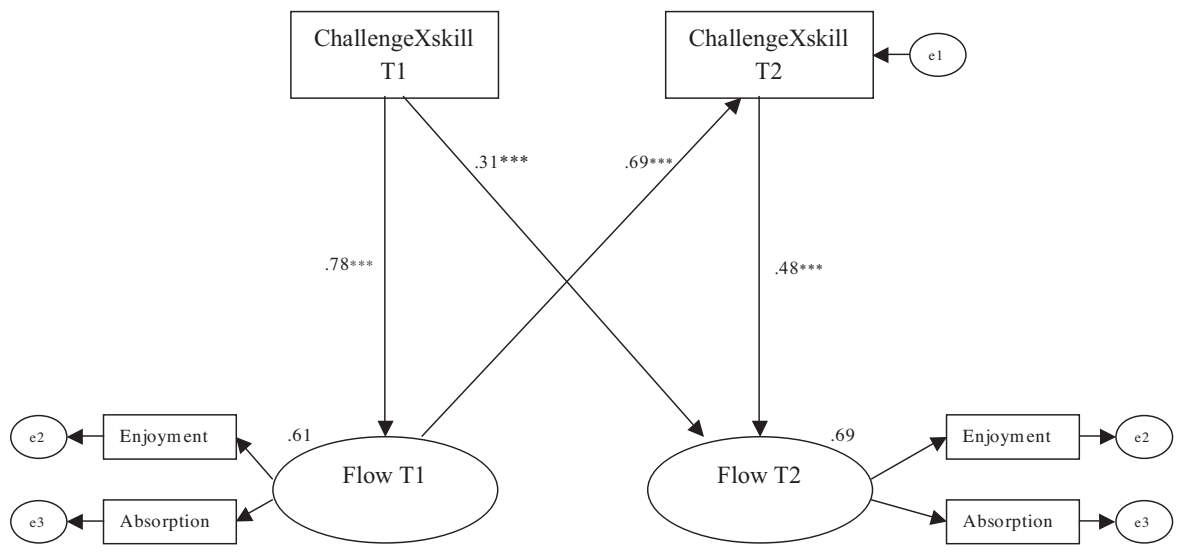

Next the second model, which extended the channel model of flow, was tested, and included self-efficacy and the challenges and skills combination as antecedents of the flow experience. As seen from Table IV, the models which included self-efficacy indicated a good fit since all the fit indices were equal to or higher than .90; even the RMSEA was smaller than .08 in all the models. The final model (M5), which did not include the reverse paths between T1 flow to T2 self-efficacy, challenges and skills T1 to T2 self-efficacy, and T2 challenges and skills, was superior to the rest of the models as it showed the best data fit, and all the fit indices met the acceptance criterion. Moreover, it presented the lowest RMSEA value of the remaining models as it was considered to indicate a good fit. Besides, the AIC and ECVI indices were also the lowest of the remaining competing models. The final model is shown in Figure 2.

\section{FIGURE 2}

Longitudinal Extended Channel Model including the multiplicative challenges and skills combination as a predictor of flow experience which results from the Structural Equation Modelling Analyses (SEM) in 258 secondary school teachers. Only significant paths are shown in this figure

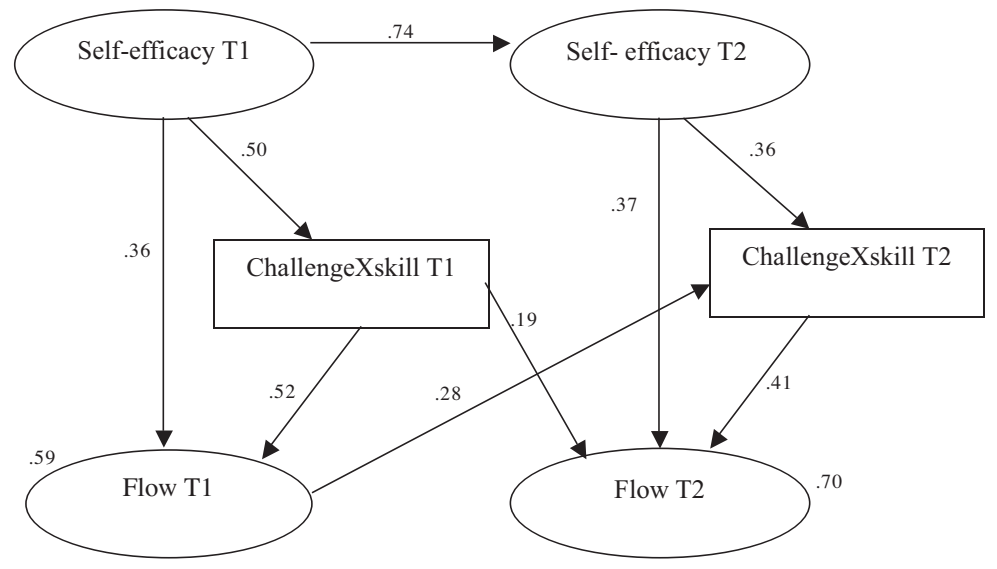


Self-efficacy and flow at work / A. Rodríguez-Sánchez et al.

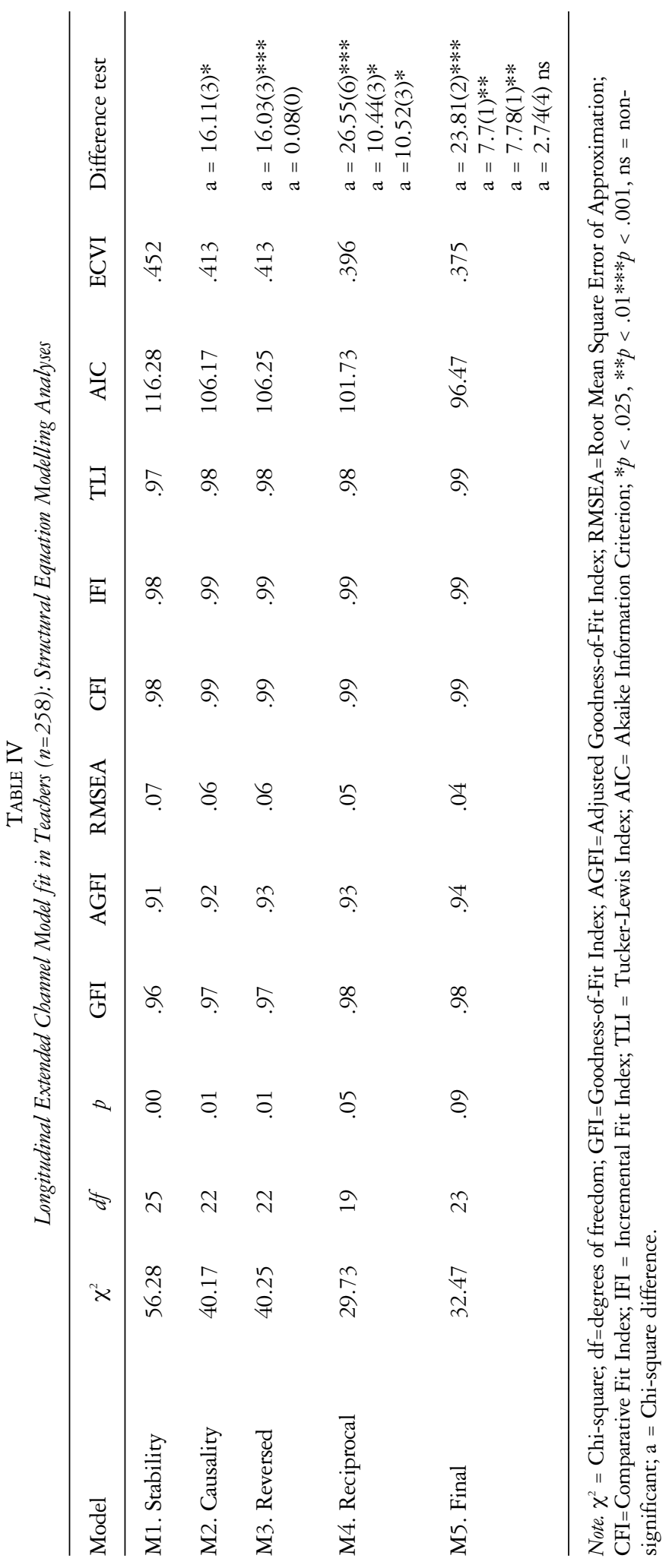


These results confirm Hypothesis 1 in which we expected that the extended channel model of flow, which included also self-efficacy as a predictor of flow experience, would show a better data fit than the original channel model of flow (which only included the challenges and skills combination). Besides, the rest of the fit indices in the extended channel model of flow showed a better fit.

Hypothesis 2 was supported as self-efficacy not only directly lead to flow experience, but also indirectly through the challenges and skills combination. From the results obtained, we observed the significant lagged and positive effects from T1 self-efficacy to $\mathrm{T} 1$ flow, from $\mathrm{T} 1$ self-efficacy to $\mathrm{T} 1$ challenges and skills, and from $\mathrm{T} 1$ challenges and skills to T1 flow. The same relationships were also shown at T2. Besides, $59 \%$ of the T1 flow variance was accounted by the hypothesised predictors, that is, T1 selfefficacy (which accounted for $21.24 \%$ of the variance) and T1 challenges and skills (which accounted for $30.68 \%$ of the variance). Regarding $70 \%$ of the T2 flow $70 \%$ variance was accounted by the hypothesised predictors, that is, T2 self-efficacy (which accounted for $25.9 \%$ of the variance), T2 challenges and skills (which accounted for $28.7 \%$ of the variance) and T1 challenges and skills (which accounted for $13.3 \%$ of the variance).

Finally, Hypothesis 3 was partially confirmed because a causal relationship was noted between T1 self-efficacy and T2 flow, which was mediated by T1 challenge and skills and T2 self-efficacy.

Furthermore, a repeated measures MANOVA test was conducted to assess if there were significant differences depending on time in the study variables and if means values of main variables (self-efficacy, challenges and skills, enjoyment and absorption) increased over time. Significant multivariate effects was found for the main effect of time $(\mathrm{T} 1, \mathrm{~T} 2)$, Wilk's Lambda $=.951, F(5,246)=0.30, p<.05$, multivariate $\eta^{2}=$ .049. The follow up repeated measures ANOVAs indicated that the main effect of time was significantly different for absorption $[F(1,246)=6.12, p<.01]$ but not for the rest of the study variables i.e. self-efficacy $[F(1,246)=1.64, p<.20]$ challenge $[F(1,246)$ $=.73, p<.29]$ skills $[F(1,246)=3.60, p<.06]$ and enjoyment $[F(1,246)=.34, p<$ .56]. Contrasts intra-subjects revealed a significant linear trend for absorption $[F(1$, $246)=6.12, p<.01]$. So, teachers increased significantly their levels of task absorption over time.

\section{DISCUSSION}

The main objective of the present work, which has focused on flow antecedents, was to extend the channel model of flow (Csikszentmihalyi, 1990, 1997) by including selfefficacy as an additional predictor of the high levels of challenges and skills combination of the flow experience itself (defined as work absorption and enjoyment). In other words, we expected self-efficacy to play a predicting role in flow experience directly and indirectly, and synchronically and diachronically, through the challenges and skills combination. The results provided evidence for our predictions. In particular, Hypotheses 1 and 2 were confirmed, favouring our extended channel model of flow. However, Hypothesis 3, which refers to the virtuous circle over time, was partially confirmed.

\section{Extending the Channel Model of Flow: self-efficacy as a flow antecedent}

As expected, the results also showed that Hypothesis 1 (the model which included self-efficacy) and the channel model of flow to be flow predictors, and which fitted the data better than the channel model of Flow with a combination of high scores on challenges and skills. Hence these data evidence that the current study contributes to improve the channel model of flow formulated by Csikszentmihalyi in 1975 and developed by Csikszentmihalyi and collaborators (Csikszentmihalyi \& 
Csikszentmihalyi, 1988; Hektner \& Csikszentmihalyi, 1996; Massimini \& Carli, 1988; Moneta \& Csikszentmihalyi, 1996; Nakamura \& Csikszentmihalyi, 2002). The current study also provides empirical evidence and supports the idea that not only the combination of high challenges and high skills is needed to experience flow, but also a belief in one's skills to overcome the challenge in the activity at hand in the future, in fact, this is our main contribution to the flow literature. In other words, although high challenges and skills are necessary, they are not sufficient conditions to experience flow. Thus the combination of Csikszentmihalyi's channel model of flow and Bandura's social cognitive theory resulted in a more complementary and complete model that explains both the flow experience and its antecedents.

This finding is closely related to Hypothesis 2 which confirmed that self-efficacy works as an antecedent directly and indirectly leads to flow through the challenges and skills combination. Our study also shows the relevant role that self-efficacy plays as an antecedent of flow experience. So far, both self-efficacy and the challenges and skills combination are prerequisites of the flow experience. This assertion is also supported by the results obtained in terms of the flow variance explained by each variable. According to these results, $21 \%$ of the variance of the T1 flow experience is explained by $\mathrm{T} 1$ self-efficacy, and $30 \%$ of the variance is explained by $\mathrm{T} 1$ challenges and skills. Likewise, these findings are replicated after 8 months at T2 when T2 self-efficacy accounted for almost $(26 \%)$ the same percentage of variance of T2 flow experience as T2 challenges and skills (29\%).

\section{Flow antecedents over time}

The results showed that $\mathrm{T} 2$ flow is accounted by $\mathrm{T} 1$ challenges and skills which, at the same time, is accounted by T1 self-efficacy. Specifically, the T2 flow variance (70.0\%) was partially explained by $\mathrm{T} 1$ challenges and skills (13\%). Unexpectedly, no direct path was found between T1 self-efficacy and T2 flow, although this cross-lag relationship was mediated by the perception of T1 challenges and skills. Apparently, it was as though feeling efficacious predicted higher levels of challenges and skills which, in turn, predicted flow experiences over time.

Since flow is a momentary experience, self-efficacy has to be very specific not only about the activity that the person is doing at that time, but also about the perception of a person's skills to overcome the challenges. In this way, the results found that T1 self-efficacy related more strongly to flow experiences, and that this situation occurred at the same time (T1) as in the flow experience, which took place 8 months later at T2. Finally, this virtuous circle was seen to occur between challenges and skills and flow over time. So, the more challenges and skills perceived at T1, the more flow experiences at $\mathrm{T} 2$, and vice versa.

\section{Limitations and future research}

Despite the relevance of this study extending the channel model of flow by taking self-efficacy as an antecedent of the flow experience, it is necessary to interpret the results with caution because of its non-experimental nature. Thus, the present study has its limitations. The first one is the use of self-report questionnaires to collect the data used in this study; specifically we decided to use adapted short scales due to parsimonious reasons. Although some research criticises the use of questionnaires since they do not yield good quality data to elicit phenomenological perceptions as subjects are not used to putting those perceptions into words (Massimini, Csikszentmihalyi, \& Carli, 1987), other research works have shown them to be a sufficient strategy to collect retrospective data of their past flow experiences and to obtain a descriptive picture of these positive experiences (for example, Chen, Wigand, \& Nilan, 2000). So this can be an alternative solution for collecting data in contexts in which it is more complicated 
to use the Experience Sampling Method (ESM; Csikszentmihalyi, Larson, \& Prescott, 1977; Csikszentmihalyi \& LeFevre, 1989) given its repeated assessment nature, although it can be used as a first step. Then, these questionnaires may be complemented with more data. For instance, one solution could be to implement diary studies to a specific sub-group from the initial questionnaire database participants in similar way that in recent literature is being done (see Nielsen \& Cleal, 2010).

Secondly, we did not have information about what kind of tasks the teachers were referring to when they completed the questionnaire (e.g., teaching, preparing classes, evaluating works). This makes it difficult to compare self-efficacy and flow levels over time because; for example, while a teacher at T1 could answer about teaching, they could be referring to preparing classes at T2. Moreover, we did not take into account that some teachers may do some bureaucratic tasks. A suggestion for future research would be to collect data about the activities that teachers do and to focus only on one such activity when answering the questionnaire at $\mathrm{T} 1$ and $\mathrm{T} 2$.

A third limitation is that this study uses two waves to allow us to explore the circle encountered since an upward trend was found in self-efficacy. In order to explore the upward-spirals in self-efficacy and flow, it would be advisable to include three time points, or more, in future research.

Fourthly, this study is limited to the secondary school teacher context. Since the main hypotheses regarding causal relationships between self-efficacy and flow were confirmed, it would be interesting and relevant to examine this phenomenon in other occupational fields. Moreover, since teamwork is gaining more and more relevance in organizations, in future research, it would be worth to study the phenomenon of flow at collective level. In other words, to study the antecedents of the concept called "shared flow" or "collective flow" (Nakamura \& Csikszentmihalyi, 2002).

Finally, a conceptual question based on the relationship between flow and engagement arises and should also be explored in future research. It is worth noting that these two concepts are very close; in fact they share the absorption variable as a common variable in both constructs. In this study we used a slightly adaptation of the absorption scale of the UWES. In fact, work engagement is defined as a persistent, pervasive and positive affective-motivational state of fulfilment in employees which does not focus on any particular object, event, individual or behaviour (Schaufeli, et al., 2002). So the difference between work engagement and flow is that the former is a more general and pervasive state of mind related to the job as such, whereas the latter is a specific optimal experience of a limited duration and relates to a specific activity. Engagement represents a more long-term, positive work-related experience with some similarities to flow at work (Demerouti, 2006). So it is plausible that engaged employees are more likely to experience short-time, transitory, optimal experiences (flow) at work compared to those who are not engaged. Further research is also needed to clarify and test the relationship of work engagement and flow.

\section{Theoretical and practical implications}

The first theoretical implication is the step forward that this study represents in the knowledge of flow antecedents, namely self-efficacy plays a key role as a flow prerequisite at a given time and also over time, as mediated by high challenges and skills. So by comparing those models which include self-efficacy, or not, as an antecedent of the flow experience, we have shown that the model fits the data better when it includes self-efficacy. This result is based on the predictions of Bandura's social cognitive theory (SCT, Bandura, 2001), and since self-efficacy is "the belief in one's capabilities to organise and execute the sources of action required to manage prospective situations" (Bandura, 1997, p. 3), and refers to the beliefs that individuals hold about their competences (in this case, about competences or skills related to work), 
it influences the perception of their skills and of the challenges to cope with. In that sense, and according to the SCT, people with high efficacy beliefs will perceive more challenges immediately, and will feel more competent (skilled) which, in turn, will influence more flow experiences over time.

In the same vein, the testing of the two models, one including the challenges and skills combination and the other including self-efficacy beliefs, represents the two theoretical approaches: the social cognitive theory (Bandura, 1997, 2001) and the flow theory (Csikszentmihalyi, 1975, 1990). The inclusion of self-efficacy in the channel model of flow is indeed a step forward, which Bassi et al. (2007) also began. The combination of these two theories has demonstrated that the more complete model including self-efficacy proves better to explain the optimal experience process.

Moreover, "SCT extends the perspective on positive psychology beyond the individual level to social and structural levels. It also provides scalable applications that can improve the lives of vast numbers of people. These sociocognitive approaches promote the betterment of people's lives in fundamental ways through enablement for positive personal and social change." (Bandura, 2011, p. 15). So far, this step forward has provided researchers with a valid and reliable information about flow experience as it can be explained by the combination of these two theoretical perspectives. A third conceptual issue is related to the relationship between self-efficacy and perceived competence. Although at first glance they may seem to be the same constructs, it must be noted that professional efficacy is one's perception of the current capabilities and skills to do a specific activity (in the present study, teaching). However, self-efficacy refers to the beliefs in one's capabilities to teach (in the present study) successfully even though the teacher encounters problems or obstacles during the activity. In other words, professional efficacy refers to the level of skills that teachers possess, while self-efficacy is the belief that the teacher can teach using his/her skills in the future. Furthermore, to avoid the possibility of overlapping problems between these two constructs, a model test has been carried out in this study. The results showed that self-efficacy and professional efficacy were interrelated but had distinct constructs.

The practical implications are twofold. First, the results obtained provide evidence of the need to (re)design jobs in order to increase the worker's challenge and skill perceptions. Thus, only those jobs characterised by high challenges performed by high skilled workers will provide those employees the chance to experience flow at work (Csikszentmihalyi, 1990; Eisenberger, Jones, Stiglhamber, Shanock, \& Randall, 2005). The opportunity to work in the contexts characterised by challenging tasks with accurate levels of skills will enhance "healthy workers" working in "healthy jobs" which, in turn, will increase positive moods (Csikszentmihalyi, et al., 1993), task interest (Catley \& Duda, 1997) and "healthy products" (Salanova, 2008). Then, as selfefficacy is a relevant antecedent to experience flow, the results suggest that training plays a pivotal role to generate flow more frequently (by increasing the perception of challenge and skills at work, but above all, self-efficacy levels). This training should focus on promoting the four sources of efficacy which include a variety of components that are consistent with the theoretical cues for self-efficacy building (Bandura, 1997, 2001). These include role-playings to provide successful experiences at work (enactive mastery), models of performance (vicarious experiences), coaching and encouragement (verbal persuasion), and reduction of the emotional threats of rejection (managing physiological states) (see Salanova et al., 2003).

In short, the present study allowed us the chance to explore and find such interesting results in relation to the antecedents of the flow experience. Specifically, the study allowed us to go beyond the challenges and skills combination as flow prerequisites by means of self-efficacy beliefs in teachers. Therefore, it has enabled us to extend the channel model of flow (Csikszentmihalyi, 1975) thanks to its combination and integration with the social 
cognitive theory (Bandura, 1997, 2001). Besides, we also conclude that, in our case, schools may facilitate flow experiences among teachers by investing in creating challenging tasks and by promoting the idea that teachers can do it.

\section{Notes}

${ }^{1}$ i.e. $\mathrm{T} 1$ absorption regarding gender $[F(1,256)=.79$, n.s. $]$, age $[F(32,225)=1.17$, n.s. $]$, teaching experience $[F(41,209)$ $=.79$, n.s. $]$ and type os school $[F(1,256)=1.00$, n.s. $]$; T2 absorption regarding gender $[F(1,256)=.16$, n.s. $]$, age $[F(32$, $225)=1.23$, n.s.], teaching experience $[F(41,209)=.99$, n.s. $]$ and type of school $[F(1,256)=.14$, n.s. $]$; T1 enjoyment regarding gender $[F(1,256)=1.75$, n.s. $]$, age $[F(32,225)=.89$, n.s. $]$, teaching experience $[F(41,209)=.91$, n.s. $]$ and type of school $[F(1,256)=.88$, n.s. $]$; and T2 enjoyment regarding gender $[F(1,256)=2.48$, n.s. $]$, age $[F(32,225)=.68$, n.s. $]$, teaching experience $[F(41,209)=.79$, n.s. $]$ and type of school $[F(1,256)=.48$, n.s. $]$.

\section{References}

AKAIKE, H. (1987). Factor analysis and AIC. Psychometrika, 52, 317-332.

Arbuckle, J. L. \& Wothke, W. (1999). Amos 4.0 user's guide. Chicago, IL: Small Waters Corp.

BAKKer, A. B. (2005). Flow among music teachers and their students: The crossover of peak experiences. Journal of Vocational Behaviour, 66, 26-44.

Bandura, A. (1997). Self-efficacy: The exercise of control. New York, NY: Freeman.

Bandura, A. (2001). Social cognitive theory: An agentic perspective. Annual Review of Psychology, 52, 1-26.

Bandura, A. (2011). A social cognitive perspective on positive psychology. Revista de Psicología Social, $26,7-20$.

Bassi, M., Steca, P., Delle Fave, A. \& Caprara, G. (2007). Academic self-efficacy beliefs and quality of experience in learning. Journal of Youth and Adolescence, 36, 301-312.

Browne, M. W. \& Cudeck, R. (1993). Alternative ways of assessing model fit. In K. A. Bollen \& J. S. Long (Eds.), Testing structural equation models (pp. 136-162). Newbury Park, CA: Sage.

Bryce, J., \& HAwOrTH, J. (2002). Well-being and flow in sample of male and female office workers. Leisure Studies, 21, $249-263$.

Caprara, G. V., Pastorelli, C., Regalia C., Scabini E. \& Bandura A. (2005). Impact of filial self efficacy on quality of family functioning and satisfaction. Journal of Research on Adolescence, 15, 71-97.

CATLEY, D., \& DudA, J. L. (1997). Psychological antecedents of the frequency and intensity of flow in golfers. International Journal of Sport Psychology, 28, 309-322.

CHEN, H. (2006). Flow on the net-detecting web users positive affects and their flow states. Computers in Human Bebaviour, $22,221-233$.

Chen, H., Wigand, R. T. \& Nilan, M. S. (2000). Exploring web users' optimal flow experiences. Information Technology E People, 13, 263-281.

CSIKSZENTMIHALYI, M. (1975). Beyond boredom and anxiety. San Francisco, CA: Jossey-Bass.

CsikszentmiHalyi, M. (1990). Flow: The psychology of optimal experience. New York: Harper \& Row.

CSIKSZENTMiHAlYI, M. (1997). Finding flow: The psychology of engagement with everyday life. New York: Basic Books.

CsiksZENTMIHALYI, M. (2003). Good Business. Leadership, flow and the making of meaning. London: Coronet Books.

Csimszentminalyi, M. \& Csikszentminalyi, I. S. (1988) Optimal experiences. Psychological studies of flow in consciousness. New York: Cambridge University Press.

Csikszentmihalyi, M., Larson, R. W. \& Prescott, S. (1977). The ecology of adolescent activities and experiences. Journal of Youth Adolescence, 6, 281-294.

Csikszentmihalyi, M., \& LeFevre, J. (1989). Optimal experience in work and leisure. Journal of Personality and Social Psychology, 56, 815-822.

Cimszentminalyi, M., Rathunde, K. \& Whalen, S. (1993). Talented teenagers: The roots of success and failure. New York: Cambridge University Press.

Delle Fave, A. \& Bassi, M. (2000). The quality of experience in adolescents' daily lives: Developmental perspectives. Genetic, Social, and General Psychology Monographs, 126, 347-367.

Delle Fave, A. \& Massimini, F. (2004). Parenthood and the quality of experience in daily life: A Longitudinal study. Social Indicators Research, 67, 75-106.

Demerouti, E. (2006). Job characteristics, flow, and performance: The moderating role of conscientiousness. Journal of Occupational Health Psychology, 11, 266-280.

Eisenberger, R., Jones, J. R., Stiglhamber, F., Shanock, L. \& Randall, A. T. (2005). Flow experiences at work: For high need achievers alone? Journal of Organizational Behavior, 26, 755-775.

Ghani, J. A. \& Deshpande, S. P. (1994). Task characteristics and the experience of optimal flow in human-computer interaction. The Journal of Psychology, 128, 381-391.

Grau, R., Salanova, M., \& Peiró, J. M. (2001). Moderating effects of self-efficacy on occupational stress. Psychology in Spain, 5, 63-74.

Hektner, J., \& Csikszentmihalyi, M. (1996). A longitudinal exploration of flow and intrinsic motivation in adolescents. Paper presented at the Annual Meeting of the American Educational Research Association, New York City.

HoYle, R. H. (1995). The structural equation modeling approach: Basic concepts and fundamental issues. In R. H. Hoyle (Ed.), Structural equation modeling, concepts, issues, and applications (pp. 1-15). Thousand Oaks, CA: Sage.

Iverson, R. D. \& Maguire, C. (2000). The relationship between job and life satisfaction: Evidence from a remote mining community. Human Relations, 53, 807-839.

Jackson, S.A., \& EkLund, R. C. (2002). Assessing flow in physical activity: The Flow State Scale-2 and Dispositional Flow Scale-2. Journal of Sport E Exercise Psychology, 24, 133-150. 
Llorens, S., Schaufeli, W. B., Bakker, A. \& Salanova, M. (2004). Does a positive gain spiral of resources, efficacy beliefs and engagement exist? Computer in Human Behavior, 23, 825-841.

Massimini, F. \& CARLI, M. (1988). The systematic assessment of flow in daily experience. In M. Csikszentmihalyi \& I. S Csikszentmihalyi (Eds.), Optimal experience: Psychological studies of flow in consciousness (pp. 288-318). New York: Cambridge University Press.

Massimini, F., Csikszentmihalyi, M. \& Carli, M. (1987). The monitoring of optimal experience: A tool for psychiatric rehabilitation. Journal of Nervous and Mental Disease, 175, 545-549.

Moneta, G. B. \& Csikszentmihalyi, M. (1996). The effect of perceived challenges and skills on the quality of subjective experience. Journal of Personality, 64, 266-310.

Nakamura, J. \& Csikszentmihalyi, M. (2002). The concept of flow. In C. R. Snyder \& S. Lopez (Eds.), Handbook of positive psychology (pp. 89-105). Oxford: Oxford University Press.

Nelson, D. \& Simmons, B. (2002). Healthy psychology and work stress: A more positive approach. In J. C. Quick \& L. E. Tetrick (Eds.), Handbook of occupational health psychology (pp. 97-119). Washington, DC: American Psychological Association.

Nielsen, K. \& Cleal, B. (2010). Predicting flow at work: Investigating the activities and job characteristics that predict flow states at work. Journal of Occupational Health Psychology, 15, 180-190.

PitTs, S. C., West, S. G. \& TeIN, J. Y. (1996). Longitudinal measurement models in evaluation research: Examining stability and change. Evaluation and Program Planning, 19, 333-350.

Rodríguez-SÁnchez, A. M., Cifre, E., Salanova, M. \& Åborg, C. (2008). Technoflow among Spanish and Swedish students: A confirmatory factor multigroup analysis. Anales de Psicología, 24, 42-48.

SAlanova, M. (2008). Organizaciones saludables: una aproximación desde la psicología positiva [Healthy organizations: an approximation from positive psychology]. In C. Vázquez \& G. Hervás (Eds.), Psicología positiva: bases científicas del bienestar y la resiliencia (pp. 403-428). Madrid: Alianza Editorial.

Salanova, M., BAKker, A. \& Llorens, S. (2006). Flow at work: Evidence for an upward spiral of personal and organizational resources. Journal of Happiness Studies, 7, 1-22.

Salanova, M., Llorens, S., Cifre, E., Martínez, I. M. \& Schaufeli, W. B. (2003). Perceived collective efficacy, subjective well-being and task performance among electronic work groups: An experimental study. Small Groups Research, 34, 4373.

Salanova, M., Llorens, S. \& Shaufeli, W. B. (2011). "Yes, I can, I feel good, and I just do it!” On gain cycles and spirals of efficacy beliefs, affect, and engagement. Applied Psycology: An International Review, 60, 255-285.

Salanova, M., Schaufeli, W. B., Llorens, S., Peiró, J. M. \& Grau, R. (2000). Desde el 'burnout' al 'engagement': ¿una nueva perspectiva? [From Burnout to Engagement: A new perspective?]. Revista de Psicología del Trabajo y las Organizaciones, 16, 117-134.

Salanova, M., Schaufeli, W. B., Xanthopoulou, D. \& Bakker, A. (2009). The gain spiral of resources and work engagement. In A. Bakker \& M. Leiter (Eds.), Work engagement: Recent developments in theory and research (pp. 118-131). New York: Psychology Press.

SAWYER, R. K. (2003). Group creativity. Music, theater, collaboration. Mahwah: Lawrence Erlbaum Associates.

SChaufeli, W. B., Leiter, M. P., MASLACH, C. \& JACKSON, S. E. (1996). Maslach Burnout Inventory - General Survey. In C. Maslach, S. E. Jackson \& M. P. Leiter (Eds.), The Maslach Burnout Inventory-Test Manual (3rd ed.) (pp. 12-26). Palo Alto, CA: Consulting Psychologists Press.

Schaufeli, W. B., Salanova, M., GonzÁlez-Romá, V. \& Bakker, A. (2002). The measurement of burnout and engagement: A confirmatory factor analytic approach. Journal of Happiness Studies, 3, 71-92.

SCHWARZER, R. (1999). General perceived self-efficacy in 14 cultures. http://www.yorku.ca/faculty/academic/schwarze/ worldl4.htm.

Seligman, M. E. P. \& Csikszentmihalyi, M. (2000). Positive psychology: An introduction. American Psychologist, $55,5-14$.

SHIN, N. (2006). Online learner's 'flow' experience: An empirical study. British Journal of Educational Technology, $37,705-$ 720 . 